WBS No.: 1.2.4.7

SCP No.: N/A

QA: N/A

TECHNICAL DOCUMENT TTILE

\title{
RETRIEVAL EQUIPMENT DESCRIPTIONS
}

DOCUMENT IDENTIFIER

BCAF00000-01717-5705-00001 REV 00

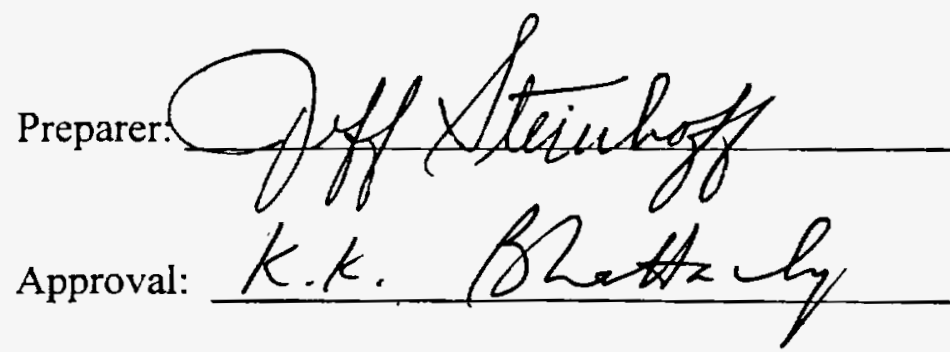

Date: $\quad 8 / 25 / 97$

Date: $\quad 8 / 27 / 97$ 


\section{EQUIPMENT DESCRIPTIONS}

\section{RETRIEVAL EQUIPMENT}

FY 1997

\subsection{OBJECTIVE AND SCOPE}

The objective and the scope of this document are to list and briefly describe the major mobile equipment necessary for waste package (WP) retrieval from the proposed subsurface nuclear waste repository at Yucca Mountain. Primary performance characteristics and some specialized design features of the equipment are explained and summarized in the individual subsections of this document. There are no quality assurance requirements or QA controls in this document.

Retrieval under normal conditions is accomplished with the same fleet of equipment as is used for emplacement. Descriptions of equipment used for retrieval under normal conditions is found in Emplacement Equipment Descriptions, DI: BCAF00000-01717-5705-00002 (a document in progress).

Equipment used for retrieval under abnormal conditions is addressed in this document and consists of the following:

1. Inclined Plane Hauler

2. Bottom Lift Transporter

3. Load Haul Dump (LHD) Loader

4. Heavy Duty Forklift for Emplacement Drifts

5. Covered Shuttle Car

6. Multipurpose Vehicle

7. Scaler

\subsection{INPUTS}

The equipment descriptions are based on the design analysis as cited below. All design assumptions and technical references as stated in this document originate from that analysis. The method used to prepare this document is to summarize the technical features and data of the major equipment discussed in the analysis.

\subsection{Design Parameters}

Refer to Waste Package Retrieval Equipment, DI: BCAF00000-01717-0200-00004 Rev 00, Section 4.1 . 
Title: Retrieval Equipment

DI: BCAF00000-01717-5705-00001 Rev 00

Descriptions

Page: 3 of 31

2.2 Criteria

Refer to Waste Package Retrieval Equipment, DI: BCAF00000-01717-0200-00004 Rev 00 , Section 4.2 .

\subsection{Assumptions}

Refer to Waste Package Retrieval Equipment, DI: BCAF00000-01717-0200-00004 Rev 00 , Section 4.3 .

2.4 Codes and Standards

Refer to Waste Package Retrieval Equipment, DI: BCAF00000-01717-0200-00004 Rev 00 , Section 4.4 .

2.5 References

2.5.1 Waste Package Retrieval Equipment, DI: BCAF00000-01717-0200-00004 Rev 00

2.5.2 Repository Subsurface Layout Configuration Analysis, DI: BCA000000-017170200-00008 Rev 00

2.5.3 Evaluation of Waste Package Transport and Emplacement Equipment, DI: BCAF00000-01717-0200-00002 Rev 00

\subsection{INTERFACES}

Refer to Waste Package Retrieval Equipment, DI: BCAF00000-01717-0200-00004 Rev 00, Section 7 .

\subsection{EQUIPMENT DESCRIPTIONS}

\subsection{Inclined Plane Hauler}

The inclined plane hauler (IPH) as depicted in Figure 4.1 would be part of a specialized train designed to load and haul a breached WP or a breached WP inside a WP transporter. The train would consist of the IPH itself and retrieval transport locomotives. The transport locomotives would be battery/trolley capable so that if the trolley were disabled, the transport locomotives would remain operable. The deck of the IPH would be designed so that the carrying position for the WP would be 2 meters or less above the invert. If an unbreached WP were to fall off the deck, it would fall 2 meters or less and would not breach. The IPH would be as wide as possible to maintain stability and still be capable of loading a WP or WP transporter from any likely location on the floor of the main drift or ramp. 


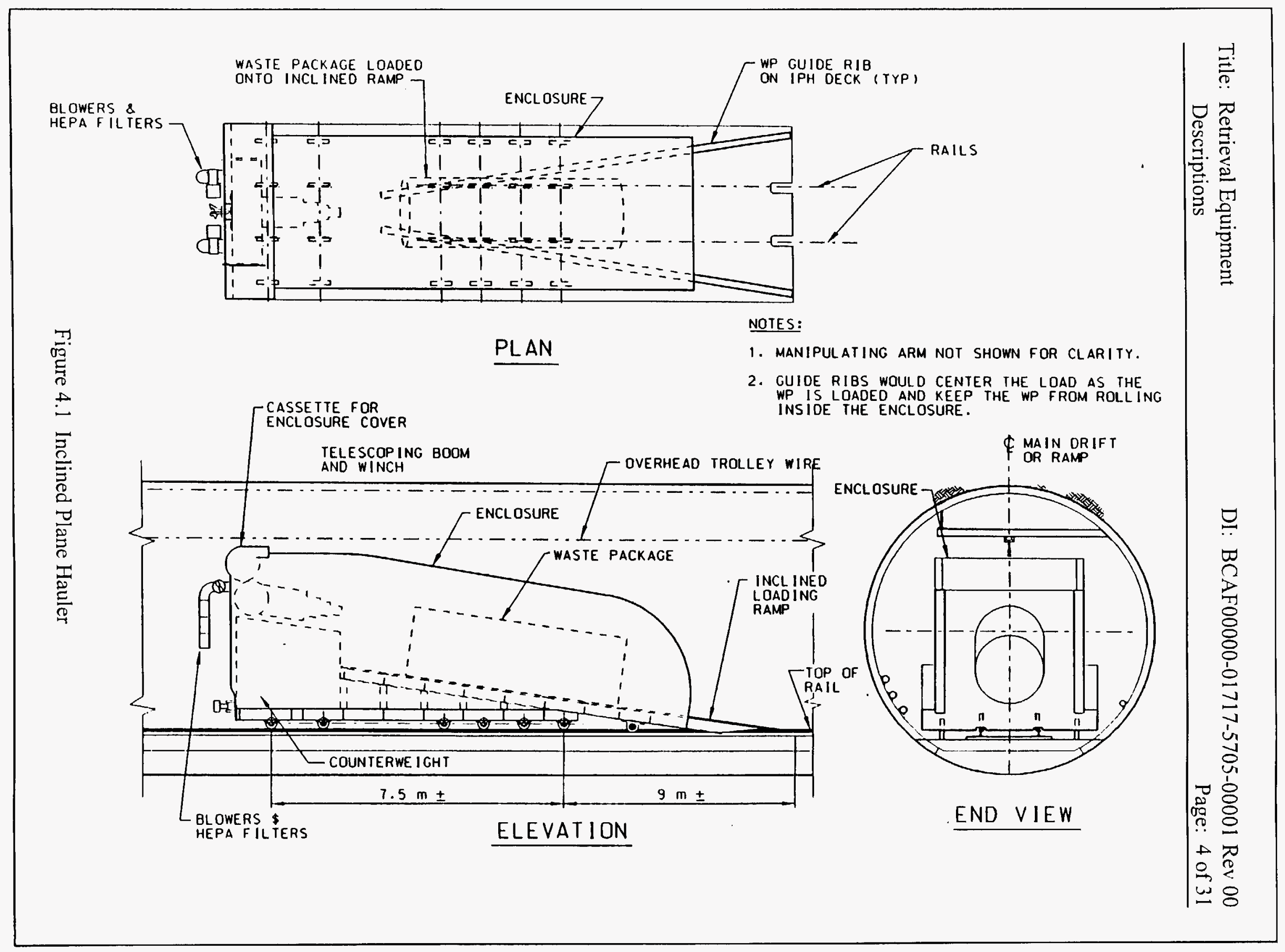


The device used to pull the load onto the deck of the IPH would consist of a manipulating arm, clevis, wire rope and an extendable boom with the load block on one end and a winch on the other end. The wire rope would extend from the load block to the clevis. The clevis would attach to the WP or WP transporter. The manipulating arm on the IPH would position the clevis at one hole on the waste package skirt or over a preexisting eye on the WP transporter. A solenoid or other device would push the bolt of the clevis through the hole. Ribs would be provided on the deck to center the load and to prevent the WP from rolling off the IPH. The winch on the extendable boom would cause the boom to retract which would pull the load onto the IHP deck.

An enclosure would be provided on the IPH to contain contamination if the WP were breached. The enclosure would be maintained under negative pressure by a blower exhausting into a HEPA filter. The enclosure would not provide shielding against radiation. Administrative controls would be used to keep personnel a safe distance from the IHP during the trip to surface.

\subsubsection{Inclined Plane Hauler Data Sheet}
A. Equipment Name:
B. Service:

C. Operating Conditions:

1. Working Environment:

2. Temperature Range:

3. Elevation:

4. Tunnel/Main Drift operating envelope

5. Tunnel/Main Drift Gradient

6. Load

7. Minimum Track Radius
Inclined Plane Hauler The bounding condition would be to load and haul a breached WP inside of a WP transporter from the floor of the main drifts or the North Ramp to the surface.
Above surface and below surface in the main drift, turnouts or the North Ramp

$27^{\circ} \mathrm{C}$ to $50^{\circ} \mathrm{C}$

Approximately 1000 to $1200 \mathrm{~m}$ above sea level.

$4.10 \mathrm{~m}$ wide $\times 5.25 \mathrm{~m}$ high

$\pm 3 \%$ maximum

Estimate total weight of WP transporter and WP is $225 \mathrm{MT}$

$20 \mathrm{~m}$ 
8. Track Gage

9. Rail

10. Rail Condition

11. Operation

12. Travel Distance

D. Equipment Requirements:

1. Construction

2. Deck

3. Radiation Shielding

4. Enclosure

5. Manipulating arm
$1.44 \mathrm{~m}$

$57 \mathrm{~kg} / \mathrm{m}(115 \mathrm{lb} / \mathrm{yd})$

Above ground varies with weather, below ground dry and good condition.

Non-repetitive operation. Details of operation will depend on the abnormal conditions.

Non-repetitive operation. Bounding travel distance is approximately $6,000 \mathrm{~m}$.

Fabricated of structural steel sections and plates with welded or bolted connections. Special alloys may be used to minimize structural members in order to meet operating envelope requirements. Controls must be compatible with remote operation.

Maximum height of the deck is $2 \mathrm{~m}$. The deck would be designed with ribs or other devices which would center the load and keep a waste package from rolling off the deck.

Adequate to protect onboard electronic devices.

Designed to prevent the escape of radioactive materials by enclosing the load and maintaining a negative air pressure inside the enclosure using an exhaust blower. The exhaust blower discharge would be filtered through a HEPA filter to prevent contamination of travelways.

Designed to locate and attach a clevis to one of three holes in the waste package skirt. 
6. Winch and boom

7. Couplers
Designed to pull the WP or the WP transporter onto the deck of the inclined plane hauler.

Designed to be compatible with transport locomotives

E. Power and Controls:

1. Power

2. Controls
$600 \mathrm{~V} \mathrm{DC}$ trolley or onboard batteries

Remote

Note: Controls will be summarized in a separate equipment description document.

F. Approximate Dimensions and Weight:

1. Overall Length

2. Overall Width

3. Overall Height

4. Overall Weight

5. Operating Speed

G. Other Features:

1. Braking

2. Operational Monitoring

3. Visual Monitoring
No restriction. Travel around the $20 \mathrm{~m}$ radius curve required

Must fit into the operating envelope of the North Ramp and the Main Drifts

Must fit into the operating envelope of the North Ramp and the Main Drifts

No restriction

Consistent with load, gradient and braking requirements
Fail-safe air brake system compatible with the transport locomotives is required.

Closed circuit TV

Lighting required 


\subsubsection{Inclined Plane Hauler Suppliers:}

The inclined plane hauler will be a specialty item manufactured from off-the-shelf components. One supplier contacted to determine if the inclined plane hauler could be built is Ederer Services, Inc., Post Office Box 24708, Seattle, WA 98124-0708. Contact: Don D. Sleight, Technical Sales Representative.

\subsection{Bottom Lift Transporter}

The bottom lift transporter shown in Figure 4.2 would be designed to load and haul a waste package from the emplacement drifts to the surface. Because the unit would be sized for emplacement drift operation and because the emplacement drift is smaller than the main drifts or ramp, it could also be used in the main drifts or ramp. Provisions to protect the rails are required. The bottom lift transporter would consist of a crawler chassis equipped with an inclined steel deck; a manipulating arm ; a winch and load block; and telescopic cylinders. The unit would be diesel powered. The winch on the bottom lift transporter must have the capacity to pull a waste package onto its deck. Using a multi-part line would ensure that the winch and boom could be manufactured to fit in the space available.

The bottom lift transporter carrier would be designed to carry the Bottom Lift Transporter and breached WP from the dock area of the emplacement drift to the surface. It would consist of a transporter car with an enclosure to prevent contaminated material from escaping and a retrieval transport locomotive(s).

The enclosure on the bottom lift transporter carrier would consist of light steel walls on three sides. The steel walls on the sides of the bottom lift transporter carrier would have guide track on top. The powered storage cassette would push the cover in place. A blower exhausting into a HEPA filter would maintain negative pressure in the Bottom lift transporter carrier to prevent radioactive material from escaping and contaminating the travelways.

\subsubsection{Bottom Lift Transporter Data Sheet}
A. Equipment Name:
Bottom Lift Transporter
B. Service:
The bounding condition would be to load a breached WP from an emplacement drift and haul it to the emplacement drift dock area. 
Title: Retrieval Equipment Descriptions
DI: BCAF00000-01717-5705-00001 Rev 00

Page: 9 of 31
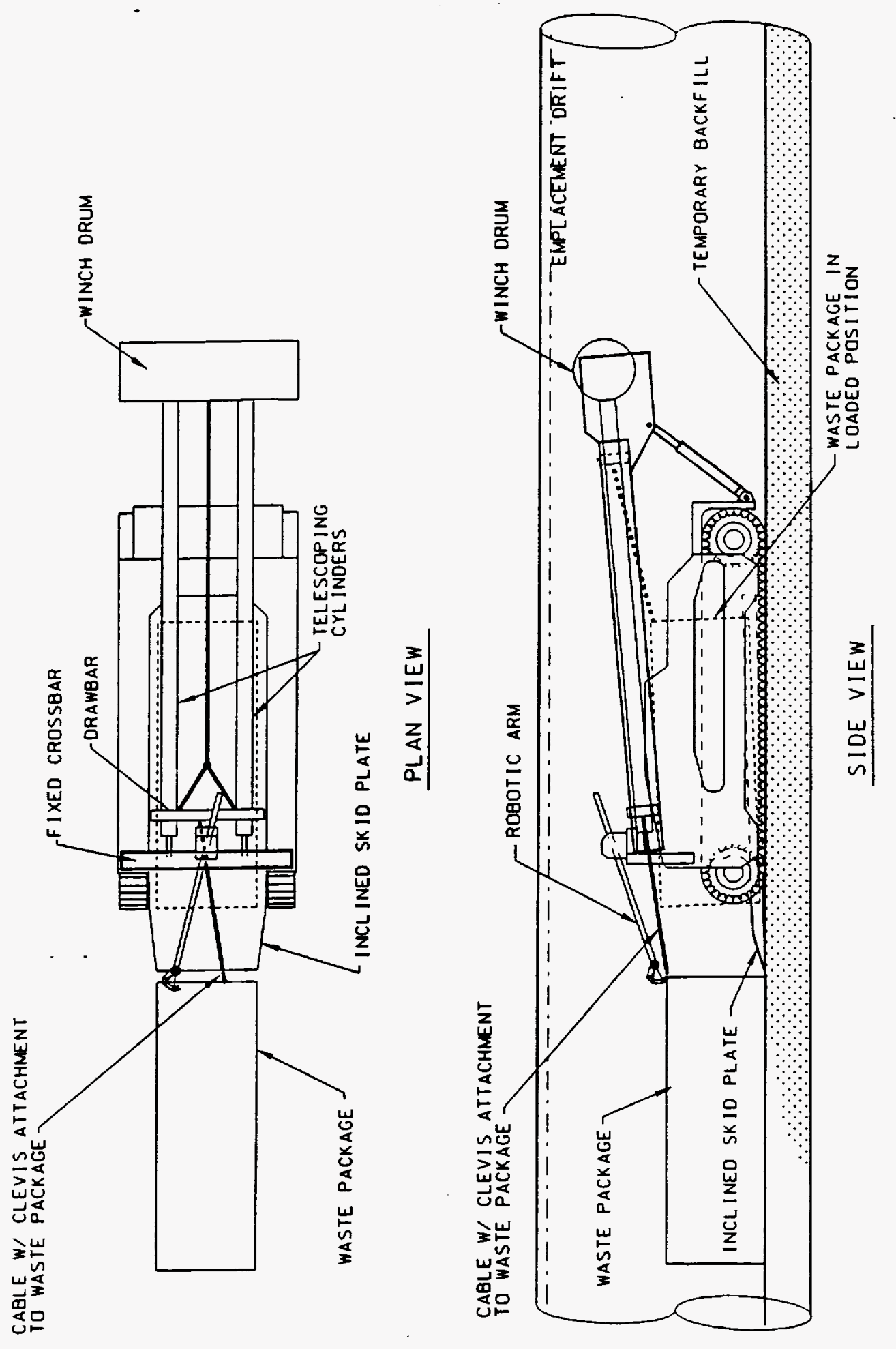

Figure 4.2 Bottom Lift Transporter 
C. Operating Conditions

1. Working Environment

2. Temperature Range

3. Elevation

4. Drift Dimension
a. Emplacement
b. Clearance
c. Gradient
$5.1 \mathrm{~m}$ dia. maximum
Adequate for remote operation
$\pm 0.75 \%$

5. Load:
a. Diameter
b. Length
c. Weight
$2.0 \mathrm{~m}$
$5850 \mathrm{~mm}$ maximum
69 MT maximum

6. Roadway

7. Power Source

8. Operation

9. Travel Distance

D. Equipment Requirements:

1. Construction
Below surface in the emplacement drifts

$27^{\circ} \mathrm{C}-50^{\circ} \mathrm{C}$

1000 to $1200 \mathrm{~m}$ above sea level

Fill material

Diesel

Non-repetitive operation. Details of operation will depend on the abnormal conditions.

Non-repetitive operation. Bounding travel distance in the emplacement drift is the total length of the emplacement drift which is approximately $1200 \mathrm{~m}$.

Fabricated of structural steel sections and plates with welded or bolted connections. Special alloys may be used to minimize structural members in order to meet operating envelope requirements. Controls must be compatible with remote operation. 
2. Deck

3. Radiation Shielding

4. Enclosure

5. Manipulating arm

6. Winch and boom

7. Crawler tracks
Deck is to be as low as possible to minimize headroom requirements

Adequate to protect onboard electronic devices.

None

Designed to locate and attach a clevis to one of three holes in the waste package skirt.

Designed to pull the WP onto the deck of the bottom lift transporter.

Designed for operation on fill material

E. Power and Controls

1. Power

2. Controls
Diesel

Remote

Note: Controls will be summarized in a separate equipment description

F. Approximate Dimensions and Weight:

1. Overall Length

2. Overall Width

3. Overall Height

4. Operating Speed
No restriction

Must fit into the operating envelope of the Emplacement Drifts

Must fit into the operating envelope of the Emplacement Drifts.

There are no minimum travel speed requirements. Estimated speed would be $1.2 \mathrm{~km} / \mathrm{hr}$.

G. Other Features: 

1. Operational Monitoring
Closed Circuit TV
2. Visual Monitoring
Lighting required

\subsubsection{Bottom Lift Transporter Suppliers}

The bottom lift transporter will be a specialty item manufactured from off-the-shelf components. One supplier contacted to determine if the bottom lift transporter could be built is $\mathrm{J} \& \mathrm{R}$ Engineering Company, Inc., 538 Oakland Avenue, P.O. Box 447, Mugwonago, WI 53149. Contact: Richard M. Savingnac, V.P - Marketing.

\subsection{Load Haul Dump (LHD) Loader}

Figure 4.3 depicts an LHD loader with a rubber tired chassis that would be used to remove rock and other debris from a ground fall in the emplacement drift, main drift or ramp. It would also be used to place fill material on the floor of the emplacement drift to form a roadway if the track were damaged. The LHD loader would be equipped with approximately $120 \mathrm{~m}$ of power cable on a reel that is integral to the machine. The cable would be attached to a portable power center wired into the power system in the main drift. The power center would be located to the side of the drift where it would not inhibit travel. The maximum distance between the loading and unloading point would be $240 \mathrm{~m}$ using this equipment. If the cable length were too short for a particular application, then a battery powered unit would be used. Portable charging stations should be considered so that batteries could be charged in adjacent drifts. The portable charging stations would be designed and operated in accordance with applicable regulations. The Heavy Duty Forklift for Emplacement Drifts is a piece of equipment that could also be equipped with an ejector bucket and function as an LHD loader. The LHD loader would also be equipped with an ejector bucket to limit dust generation during unloading. Dust would be controlled because the distance that debris falls as it is unloaded from the bucket would be minimized. The ejector bucket would push the load out rather than tipping the bucket and letting the load fall. The use of remotely controlled LHD loaders in mining is common. 
Title: Retrieval Equipment

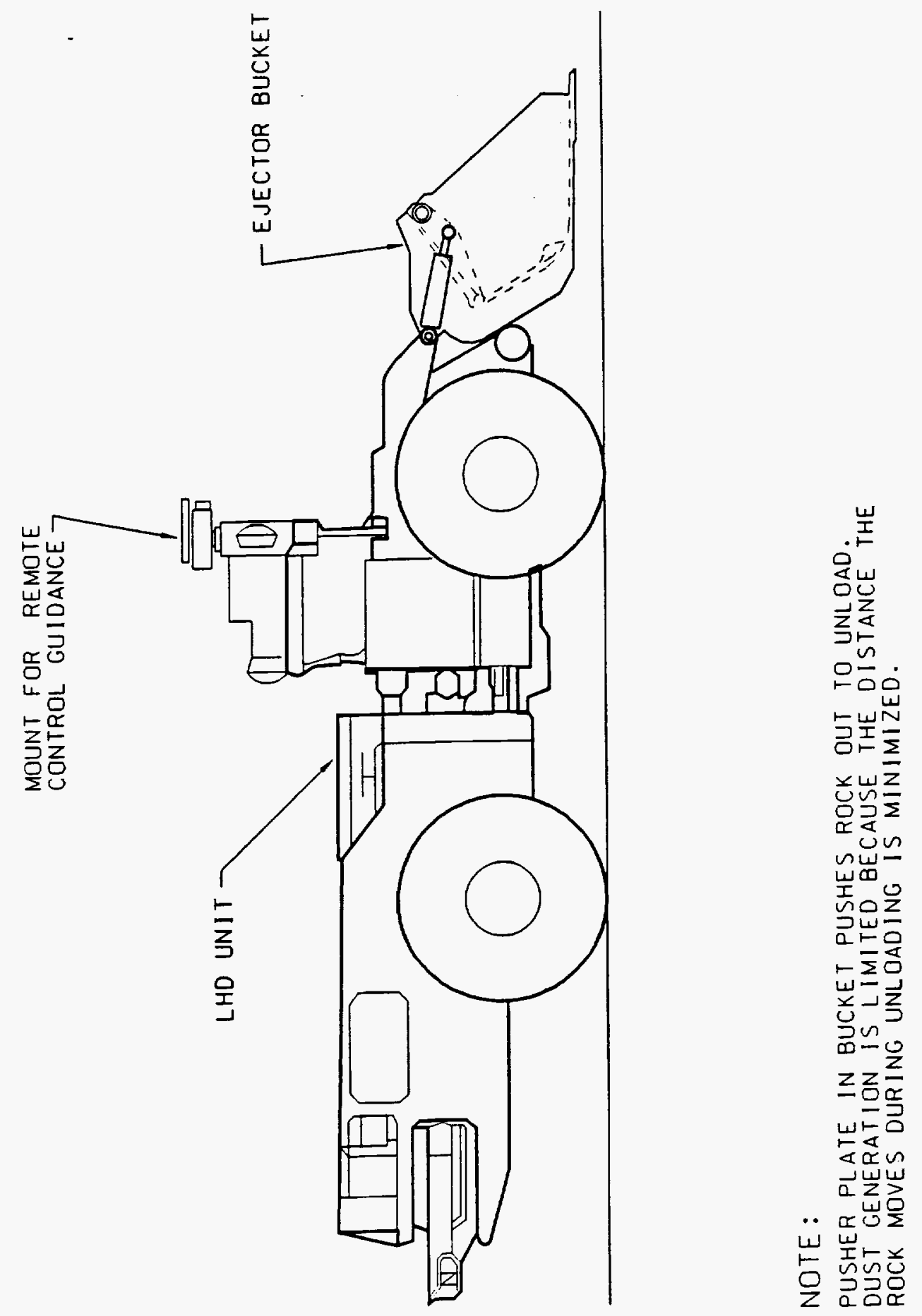

Figure 4.3 LHD Loader with Ejector Bucket 


\subsubsection{LHD Data Sheet}
A. Equipment Name
Load Haul Dump (LHD) Loader
B. Service
To place fill material on the floor of the emplacement drift to form a roadway and to remove rock and other debris from a ground fall in the emplacement drift, main drift or ramp and dump it into a covered shuttle car in a manner that will minimize dust.

C. Operating Conditions

1. Working Environment

2. Temperature Range .

3. Elevation

4. Tunnel/Drift Clearances

a. Emplacement Drifts

b. Gradient

5. Load

6. Power Source

7. Travel distance
Bounding condition is operation in the emplacement drifts underground

$27^{\circ} \mathrm{C}-50^{\circ} \mathrm{C}$

Approximately 1000 to $1200 \mathrm{~m}$ above sea level

The bounding condition is operation in the emplacement drifts which are $5.1 \mathrm{~m}$ inside diameter

The bounding condition is operation in the ramps with a maximum gradient of $3 \%$.

There is no specific load. Oversized material would be broken up with other equipment. The capacity of the loader would be determined by the size of an LHD loader that will fit into the operating envelope available in the emplacement drifts.

Would operate from power centers wired to power in the main drifts.

Approximately $120 \mathrm{~m}$ from a portable power center or $600 \mathrm{~m}$ for a battery powered unit. 
D. Equipment Requirements

1. Construction

E. Power and Controls
Standard articulated, rubber-tired chassis for used in underground applications. Controls must be compatible with remote operation.
1. Power

2. Controls
Voltage available in the Main Drift

Remote

Note: Control features for the LHD loader will be summarized in a separate equipment description document

F. Approximate Dimensions and Weight

1. Overall Length

2. Overall width

3. Overall Height

4. Overall Weight

G. Other Features

1. Ejector Bucket

2. Operational Monitoring
There is no restriction on overall length

Must fit into the operating envelope of the Emplacement Drifts

Must fit into the operating envelope of the emplacement Drifts

There is no restriction on overall weight
Bucket for a LHD that unloads by pushing rock out of the bucket rather than tipping to dump.

Closed circuit TV 
3. Visual Monitoring Lighting required

\subsubsection{Suppliers}

LHD loaders and ejector buckets are off-the-shelf items.

A. For LHD loaders

Tamrock EJC USA, Inc., 4720 Lima Street, Denver, CO 80239

B. For Ejector Bucket

Wagner Mining Equipment Company, Inc.,P.O. Box 20307, Portland, Ore. 97220

\subsection{Forklift for Emplacement Drifts}

Figure 4.4 depicts a forklift for use in the emplacement drifts. Because units sized to work in the emplacement drifts would be smaller than units sized to work in the main drifts or ramp, the forklift depicted could also work in the main drift or ramps. The forklift would be battery powered with the capacity to lift $1 / 2$ the weight of a waste package. That capacity would enable the forklift to align the waste package for other equipment that would lift and carry it. The rated capacity of the forklift depicted in the figure is $32,000 \mathrm{~kg}$ at a distance of $1575 \mathrm{~mm}$ from the boom. It is likely that the machine could be modified to lift the full load at a distance much closer to the boom. The forklift has been developed as a multipurpose machine and could be equipped with an ejector bucket. 
Title: Retrieval Equipment Descriptions

DI: BCAF00000-01717-5705-00001 Rev 00

Page: 17 of 31
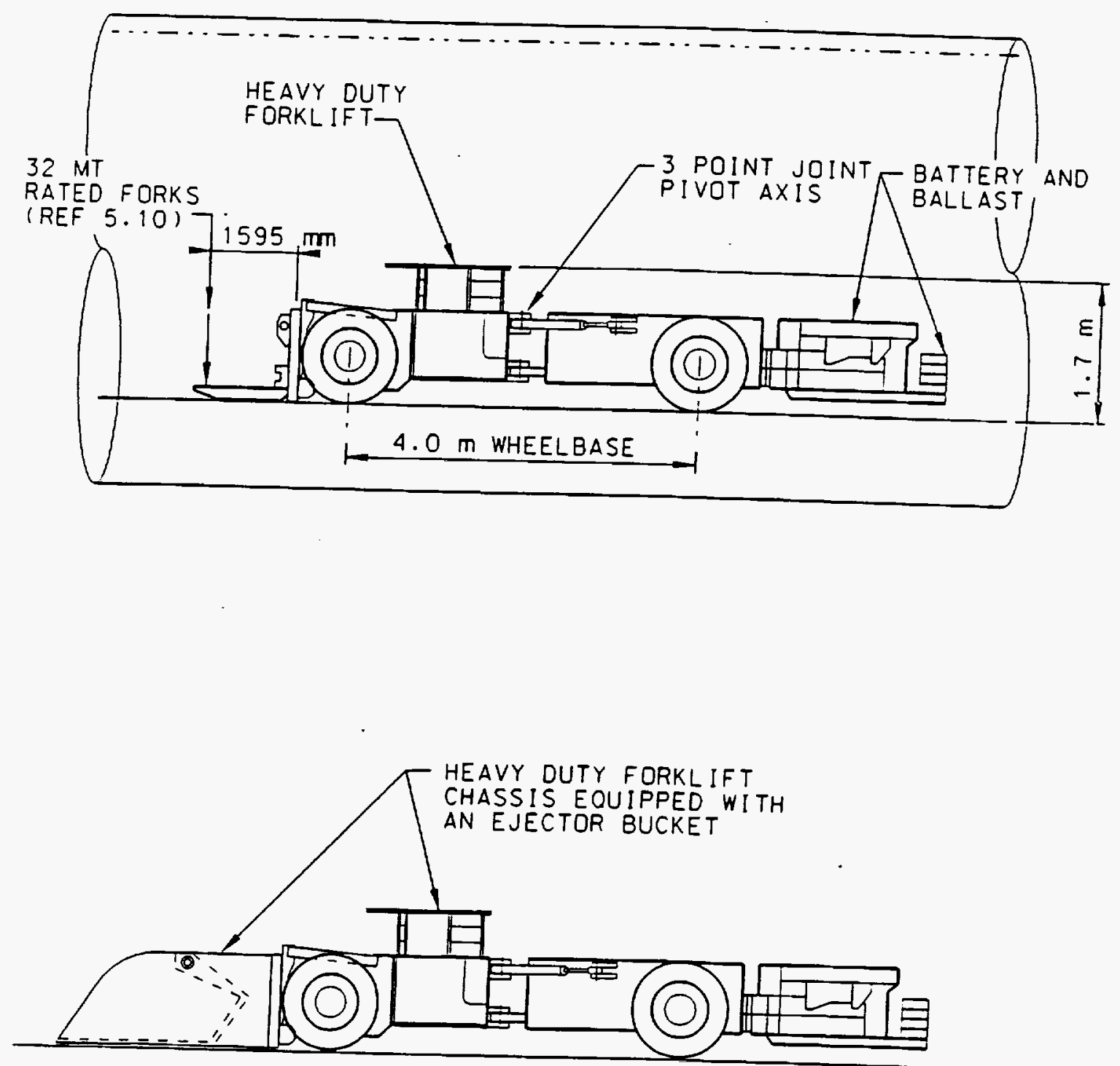

Figure 4.4 Forklift for Emplacement Drifts 
Title: Retrieval Equipment

DI: BCAF00000-01717-5705-00001 Rev 00

Descriptions

Page: 18 of 31

4.4.1 Forklift for Emplacement Drifts Data Sheets

A. Equipment Title

B. Service

C. Operating Conditions -

1. Working Environment

2. Temperature Range

3. Elevation

4. Drift Dimensions

a. Emplacement

b. Clearance in emplacement drift

c. Gradient

5. Load

6. Power Source

7. Travel Distance

D. Equipment Requirements
Forklift for Emplacement Drifts

When used as a forklift, to align a WP that may have moved from the center of the drift by an abnormal event. When used as an LHD, to place fill material on the floor of the emplacement drift to form a roadway and to remove rock and other debris from a ground fall in the emplacement drift, main drift or ramp and dump it into a covered shuttle car in a manner that will minimize dust.

Bounding condition is operation in the emplacement drifts

$27^{\circ} \mathrm{C}-50^{\circ} \mathrm{C}$

Approximately 1000 to $1200 \mathrm{~m}$ above sea level

$5.1 \mathrm{~m}$ inside diameter (Bounding Condition)

Adequate for remote operation

$\pm 3 \%$ Bounding condition for use in Ramps

Must be able to lift $34.5 \mathrm{MT}$

Battery

$600 \mathrm{~m}$ in emplacement drift 
1. Construction Standard, articulated, rubber tired chassis for underground use. Controls must be compatible with remote operation.

E. Power and Controls
1. Power
Onboard battery
2. Controls
Remote

Note: Control features for the emplacement gantry will be summarized in a separate equipment description document.

F. Approximate Dimensions and Weight

1. Overall Length

2. Overall Width

3. Overall Height

4. Operating Weight
There is no restriction on the overall length The unit must fit into the operating envelope of the emplacement drifts

The unit just fit into the operating envelope of the emplacement drifts

There is no restriction on the weight of the unit

G. Other Features

1. Multipurpose operation Must be developed as a multipurpose unit for use as an LHD or other utility vehicle

2. Ejector Bucket See Section 4.3.1.G

3. Operation Monitoring Closed Circuit TV

4. Visual Monitoring Lighting required 


\subsubsection{Forklift for Emplacement Drifts Suppliers}

Eimco Coal Machinery, Inc., Rt. 52 (a) Airport Road, Bluefield, WV 24701

Ejector Bucket Supplier - See Section 4.3.3

\subsection{Covered Shuttle Car}

Figure 4.5 shows an LHD loader dumping into a covered shuttle car. Covered shuttle cars with chain conveyor floors would be used to haul rock and other debris recovered from an emplacement drift by an LHD loader. The cars would be covered to control dust generated during loading and traveling. In operation, the ejector bucket on the LHD loader would push rock and other debris into the shuttle car. The chain conveyor on the bottom of the car would move the rock or other debris away from the LHD loader toward the other end of the shuttle car. Dust generation would be limited because the rock or debris is pushed out of the LHD loader into the shuttle car rather than being dumped. Additionally, the shuttle cars could be equipped with exhaust fans that would keep the rock box under negative pressure.

\subsubsection{Covered Shuttle Car Data Sheet}
A. Equipment Title
Covered Shuttle Car
B. Service
Operation in the main drift or north ramp to haul rock or debris.

C. Operating Conditions
1. Working Environment drifts or ramp

2. Temperature Range

$27^{\circ} \mathrm{C}-50^{\circ} \mathrm{C}$

3. Elevation

Approximately 1000 to $1200 \mathrm{~m}$ above sea level

4. Tunnel Dimensions
a. Tunnel Diameter
$7.02 \mathrm{~m}$ inside diameter
b. Gradient
$\pm 3 \%$ Maximum
5. Load
9 cubic meters 
Title: Retrieval Equipment

DI: BCAF00000-01717-5705-00001 Rev 00 Descriptions

Page: 21 of 31

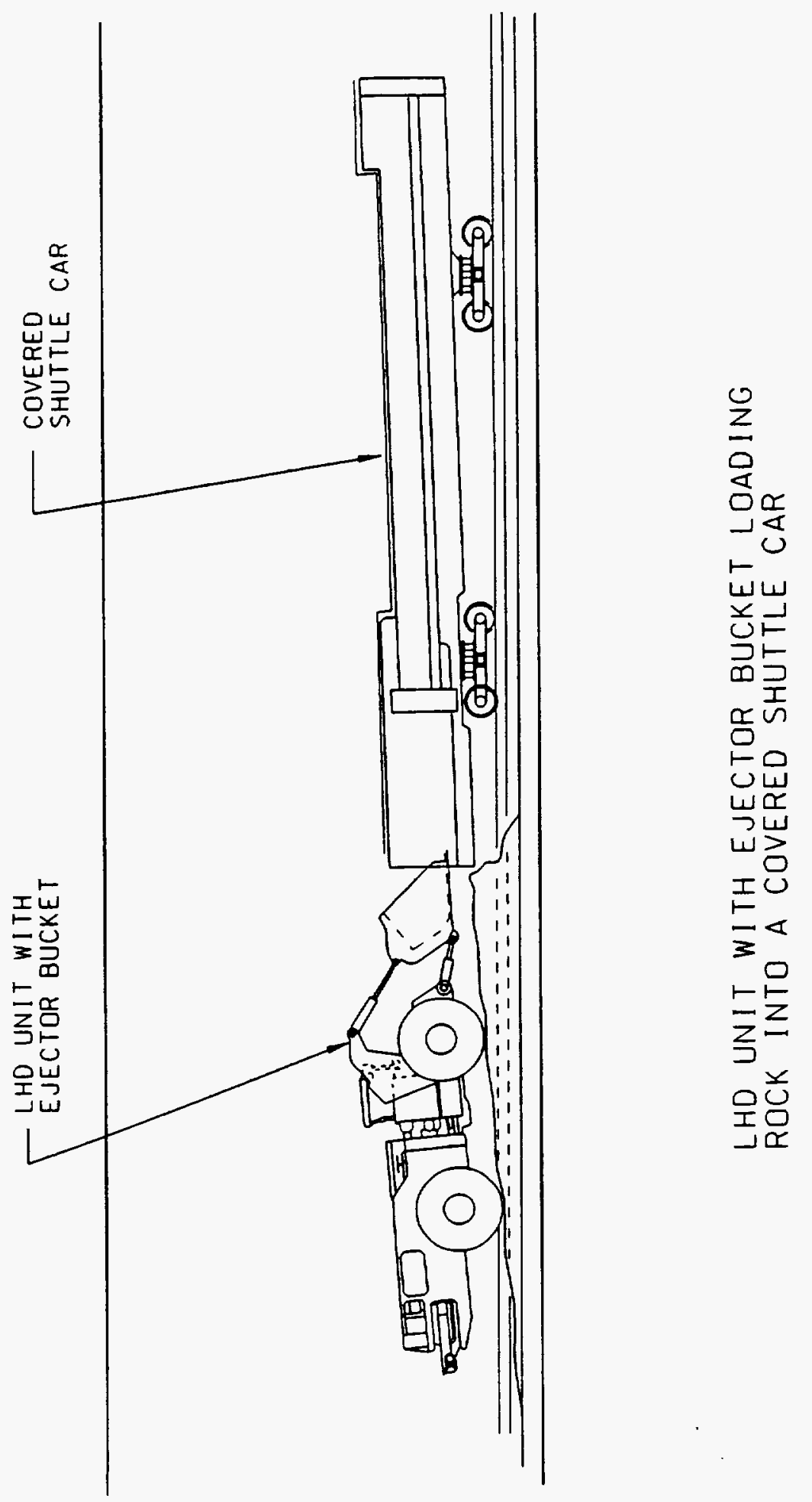

Figure 4.5 LHD loader dumping into a covered shuttle car 
6. Minimum Turning radius $20 \mathrm{~m}$

7. Track gage $\quad 1.44 \mathrm{~m}$ (56.5 inches)

8. Rail

$57.0 \mathrm{~kg} / \mathrm{m}(115 \mathrm{lb} / \mathrm{yd})$

9. Rail condition

Above surface varies with weather, below surface dry and in good condition

10. Power Source

Pulled by Transport locomotives. Operation of chain conveyor - compressed air

11. Operation . Not a cyclical operation. Would haul material from the site of an abnormal event.

12. Travel distance

Not a cyclical operation. Would haul material from the site of an abnormal event.

E. Equipment Requirements

1. Construction

Standard construction for rail cars used underground

2. Couplers

Designed to be compatible with transport locomotives

E. Power and Controls

1. Power

2. Controls
Compressed air to operate chain conveyor

Remote

Note: Controls will be summarized in a separate equipment description

F. Approximate Dimensions and Weight 
1. Overall Length

2. Overall Width

3. Overall Height

4. Overall Weight

5. Operating Speed
No Restriction. The unit must be able to travel around the $20 \mathrm{~m}$ radius curve in the turnout area.

Must fit into the operating envelope of the North Ramp and the Main Drifts

Must fit into the operating envelope of the North Ramp and the Main Drifts

No Restriction

There is no minimum travel or chain operating speed requirement

G. Other Features

1. Braking

2. Loading

3. Cover

4. Operational monitoring

5. Visual monitoring
Fail-safe brake system compatible with the transport locomotives is required.

The car will be loaded on one end by an LHD loader with an ejector bucket

The cover on the car is to limit the amount of dust generated during loading and during travel. It acts as an enclosure as described in section 4.1.1.D.4.

Closed circuit TV

Lighting required

\subsection{Multipurpose Vehicle}

A mobile, multipurpose vehicle as depicted in Figure 4.6 would be used to perform several cleanup functions as follows:

1. When the multipurpose vehicle is equipped with a hydraulic impact hammer, it would be used to reduce the size of material so that it would fit into the bucket of the LHD loader. 
Title: Retrieval Equipment

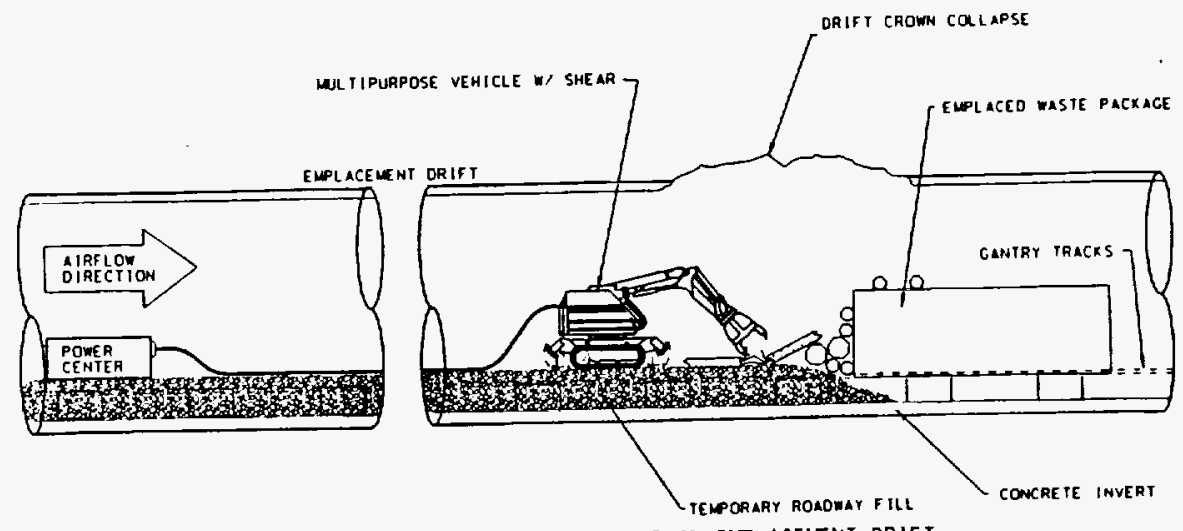

ELEVATION - HYDRAUL IC SHEAR IN EMPLACEMENI DRIFT

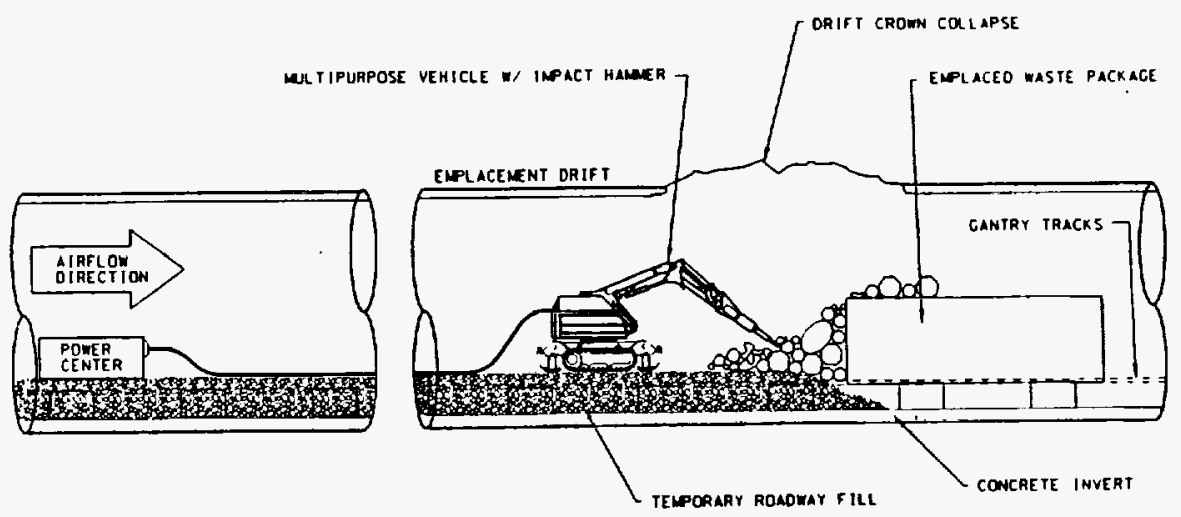

ELEVATION - IMPACT HALMER IN EMPLACEMENT ORIFT

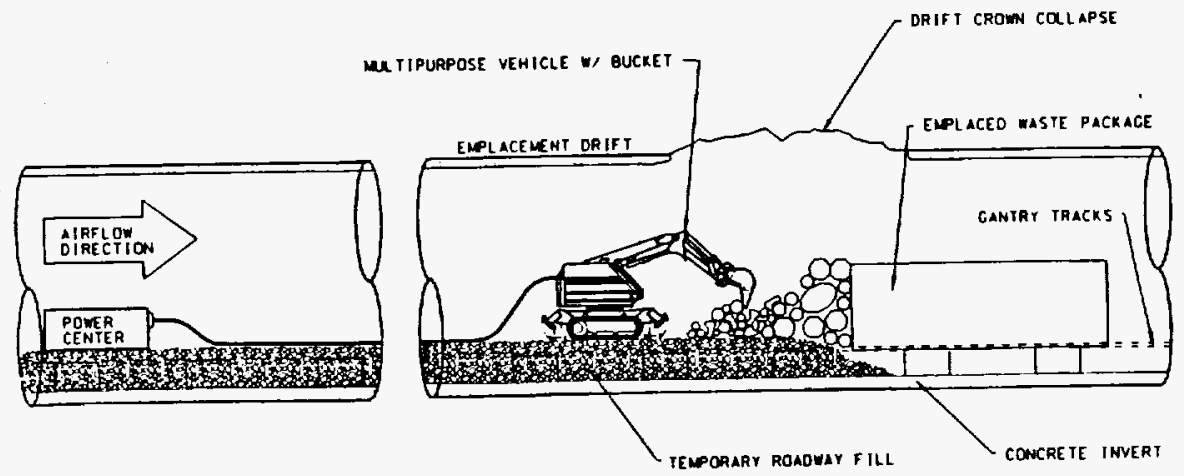

ELEVATION - LOADING BUCKET IN EMPLACEMENT DRIFT

Figure 4.6 Multipurpose Vehicle 
2. When the multipurpose vehicle is equipped with a bucket attachment, would rake debris off the WP and scrape it into a pile so that it could be picked up with the LHD loader. Since the pedestals are modular and removable, they could be removed to facilitate removal of fill material. The multipurpose vehicle could then be used to remove the fill material and place it in a pile for removal by an LHD or other equipment.

3. When equipped with a demolition shears, cut reinforcing steel.

Reinforcing steel in the tunnel liner could consist of rebar or steel fibers. If rebar is used, then the demolition shears would be used.

This equipment would be operated under remote operation from a central control station. The particular unit shown in the figures and described in the attachment is relatively small and would be powered by an electrical cable. Larger units are available. The multipurpose vehicle with appropriate equipment could measure radiation, airborne contamination and surface contamination. Surface contamination would be detected using surface smears. The unit would be used in the main drifts or ramp where conditions would preclude occupancy by humans. The unit would be known as a multipurpose inspection vehicle when used in this mode.

\subsubsection{Multipurpose Vehicle Data Sheet}
A. Equipment Title
B. Service

\section{Multipurpose Vehicle}

Used in the emplacement drifts to reduce the size of material so that it would fit into the bucket of the LHD loader; to rake debris off the WP and scrape it into a pile so that it could be picked up with the LHD loader; to remove fill material and place it in a pile for removal by an LHD or other equipment; to cut reinforcing steel; and to take radiological measurements at the location of abnormal events. 
C. Operating Conditions

1. Working Environment Emplacement drifts underground

2. Temperature

$27^{\circ} \mathrm{C}-50^{\circ} \mathrm{C}$

3. Elevation

4. Tunnel/Drift Clearances.
a. Emplacement
$5.1 \mathrm{~m}$ inside diameter
b. Gradient
$\pm 0.75 \%$

5. Power source

6. Travel distance

D. Equipment Requirements

1. Construction
Approximately 1000 to $1200 \mathrm{~m}$ above sea level

Would operate from power centers wired to power in the main drifts.

$500 \mathrm{~m}$
The following are required:

Boom designed for loads imposed by tools including bucket, shear, impact hammer and manipulating arm for taking radiologic measurements.

Quick hitch required to change tools. Undercarriage with crawler tracks for operation on fill material.

Turntable required for slewing action Controls must be compatible with remote operation.

Cable guide required to hold cable clear of the machine. 
E. Power and Controls

1. Power

From portable power center wired to power system in the main drift

2. Controls Remote

F. Approximate Dimensions and Weight

1. Overall Length

2. Overall Width

3. Overall Height

4. Overall Weight

G. Other Features

1. Impact hammer

2. Shear

3. Operational

Monitoring

4. Visual Monitoring
Must be able to slew in emplacement drift operating envelope

Must be able to operate in emplacement drift operating envelope

Must be able to operate in emplacement drift operating envelope

Must be able to operate on fill material.

\subsubsection{Multipurpose Vehicle Supplier}

North American Sales, Inc., 1144 Village Way, Monroe, WA 98727

\subsection{Scaling Machine}

A scaling machine as shown in 4.7 would be used to stabilize the roof and walls of a tunnel after a fall of ground. It would knock down loose material from the roof and walls 
Title: Retrieval Equipment

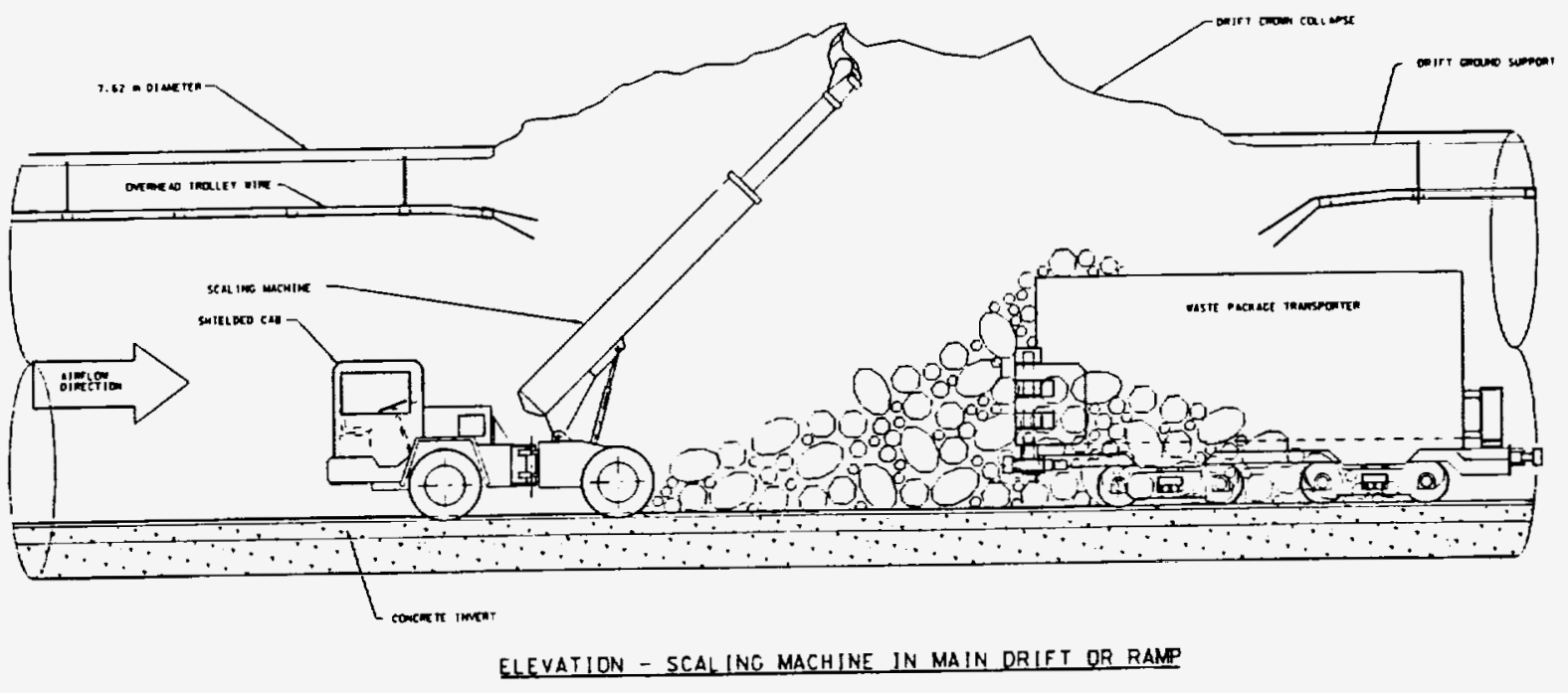

Figure 4.7 Scaling Machine 
of the tunnel until a stable arch was formed. The scaling machine would be sized so that it could be used in either the emplacement drifts, main drifts or the ramp. The scaling machine would be equipped with a shielded cab so that manual operation was possible.

\subsubsection{Scaling Machine Data Sheet}

A. Equipment Name

B. Service

C. Operating Conditions

1. Working Environment

2. Temperature Range

3. Elevation

4. Tunnel/Drift Clearances
a. Mains
b. Emplacement
Drift

5. Gradient

6. Power Source

7. Operation

8. Travel distance

D. Equipment Requirements

1. Construction
Scaling Machine

The scaling machine knocks down loose material from the floor and walls of the tunnel until a stable arch is formed.

Below surface in the emplacement drifts, the main drifts and the North Ramp

$27^{\circ} \mathrm{C}-50^{\circ} \mathrm{C}$

1000 to $1200 \mathrm{~m}$ above sea level

4.1 wide $\times 5.25 \mathrm{~m}$ high

$5.1 \mathrm{~m}$ inside diameter

$\pm 3 \%$ (Bounding Condition)

Diesel

There is no repetitive operating cycle

$4000 \mathrm{~m}$ to $6000 \mathrm{~m}$

Standard, articulated, rubber tired chassis for underground use. 
E. Power and Controls
1. Power
Diesel engine
2. Controls
Onboard operation

F. Approximate Dimensions and Weight

1. Overall Length

2. Overall Width

3. Overall Height

4. Overall Weight

G. Other Features

1. Boom

2. Shielded Cab
No restriction on overall length

Must fit in the operating envelope of the emplacement drift (Bounding Condition)

Must fit in the operating envelope of the emplacement drift

Must be able to operate on a roadway of fill material

Boom must be able to fold down so that it can maneuver in the emplacement drifts. It must be extendable so that it can reach the top of a roof collapse area. Must be designed to remove loose rock with a pick rather than by impact.

Must meet the requirements of 10 CFR 20

4.7.2 Scaling Machine Suppliers

Getman Corporation, P.O. Box 70, 6998 34th Ave., Bangor, MI 49013 
Title: Retrieval Equipment

DI: BCAF00000-01717-5705-00001 Rev 00

Descriptions

Page: 31 of 31

\subsection{CONCLUSION}

The equipment described in this document has been identified in a related design analysis during fiscal year 1997 and it was found to be most suitable for the retrieval of waste packages under abnormal conditions. All of the recommended mobile equipment will be one-of-a-kind but can be manufactured from off-the-shelf components. 